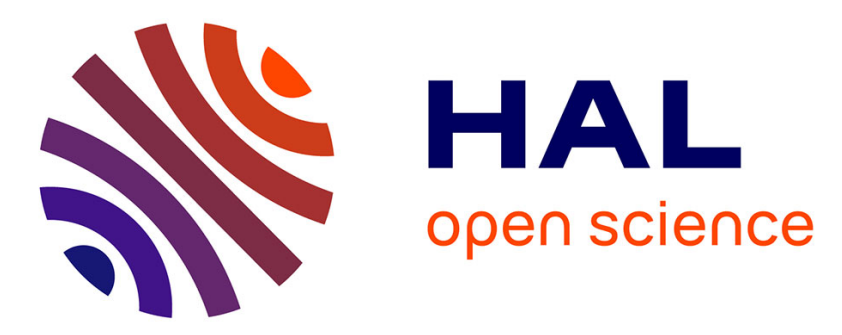

\title{
Some Approaches Derived from UniGlyph to Allow Text Input on Tiny Devices Such as Connected Watches
}

\author{
Franck Poirier, Mohammed Belatar
}

\section{To cite this version:}

Franck Poirier, Mohammed Belatar. Some Approaches Derived from UniGlyph to Allow Text Input on Tiny Devices Such as Connected Watches. Human-Computer Interaction International 2015, Aug 2015, Los Angeles, United States. pp.554 - 562, 10.1007/978-3-319-20916-6_51 . halshs-01427323

\section{HAL Id: halshs-01427323 \\ https://shs.hal.science/halshs-01427323}

Submitted on 5 Jan 2017

HAL is a multi-disciplinary open access archive for the deposit and dissemination of scientific research documents, whether they are published or not. The documents may come from teaching and research institutions in France or abroad, or from public or private research centers.
L'archive ouverte pluridisciplinaire HAL, est destinée au dépôt et à la diffusion de documents scientifiques de niveau recherche, publiés ou non, émanant des établissements d'enseignement et de recherche français ou étrangers, des laboratoires publics ou privés.

\section{(ㄷ)(1) $\$$}

Distributed under a Creative Commons Attribution - NonCommerciall 4.0 International 


\title{
Some approaches derived from UniGlyph to allow text input on tiny devices such as connected watches
}

\author{
Franck Poirier*, Mohammed Belatar** \\ * Lab-STICC, University of Bretagne-Sud, France \\ franck.poirier@univ-ubs.fr \\ ** Technology \& Telecom, Maroc \\ mohammed.belatar@gmail.com
}

\section{EXTENDED ABSTRACT}

KEYWORDS: Text Input, Virtual Keyboard, Connected Watch, Internet of Things.

\section{Introduction}

In this paper, we will first recall our approaches of text entry and more particularly Uniglyph, a text input method for handheld devices that used a 4-button keyboard. Secondly, we will describe different adaptations of Uniglyph for connected devices such as smartwatches.

\section{Smartwatches}

In fact smartwatches are wearable computers on the wrist that in addition to providing the time give access to some functionalities of the smartphone. For example, the user can directly answer or make calls from his/her wrist, receive a notification of a message, take a snapshot or a short video... It is important to note that an essential functionality is absent from smart watches, currently it is not possible to enter text directly on a virtual keyboard displayed on the watch screen.

You must use the vocal assistant built-in application to communicate (S Voice on Android, Siri on IOS). The problem is that voice communication is not always possible or appropriate to the context of user interaction. Voice communication is provided because there is currently no effective virtual keyboard on smartwatches.

From our point of view, text entry is a major functionality that should be present on all mobile or wearable devices [MacKenzie S. and Tanaka-Ishii, 2007].

In this paper, we propose some ways for text entry on smartwatches derived from Uniglyph. We call this approach UniWatch.

\section{Uniglyph text input method}

UniGlyph [Poirier and Belatar, 2007] is a text entry method for handheld devices derived from Glyph [Poirier, 2005], [Poirier, 2012]. The methods of the Glyph family are based on the structure of Latin characters composed by a specific sequence of primitives (curve, stroke, loop...).

For UniGlyph, the set of primitive shapes is reduced to only 3 symbols: (1) diagonal stroke, (2) curve and (3) horizontal or vertical line. Each letter is represented by only one input primitive according, the letter entry follows a very simple rule (figure 1):

- if the capital letter contains a diagonal stroke, then click on the "diagonal" key (1); 
- otherwise, if it contains a loop or a curving stroke, then click on the "loop" key (2);

- otherwise, click on the "straight" key (3).

As there are many more characters than primitives, each primitive corresponds to a set of letters. The expected word is deduced by a linguistic predictor like for all the ambiguous keyboards $\left(T 9 \AA\right.$, SureType ${ }^{\circledR}$, iTap $\left.{ }^{\circledR} \ldots\right)$.

The UniGlyph keypad contains three shape keys and one command key used to jump to the different input modes and to select the expected word.

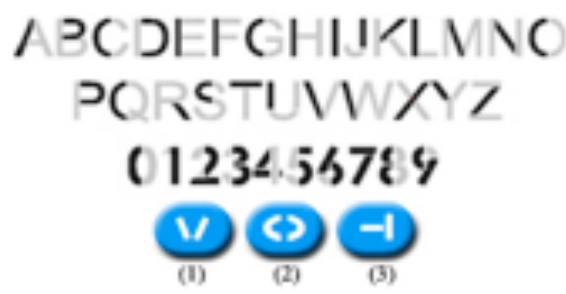

Figure 1: The UniGlyph character set and the associated input keys.

\section{UniWatch: an adaptation of UniGlyph for tiny connected devices}

The smartwatch screen is very small, from 1.2 (Pebble) to 1.6 inches (Galaxy Gear). So, it is impossible to finger tap on a complete keyboard on such a so tiny screen in order to enter text. A smartwatch screen can just contain a small number of keys, buttons or icons. It is conceivable to enter text on a small keyboard only if the keyboard contains just a few buttons.

The UniGlyph approach is a good candidate for text entry on smartwatches because it minimizes the keypad to only 4 keys, even 3 if the commands are entered by a gesture directly applied on the watch.

UniWatch, the adapted version of UniGlyph that requires only three keys is especially well suited to input text on a smartwatch.

In this paper, we propose different ways for entering text on the smartwatch screen with UniWatch.

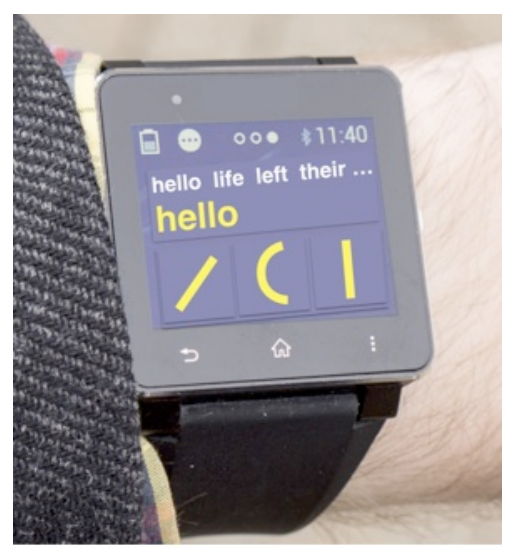

a

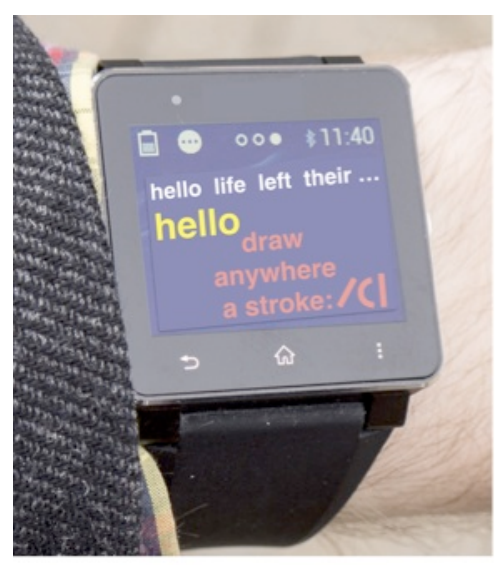

b

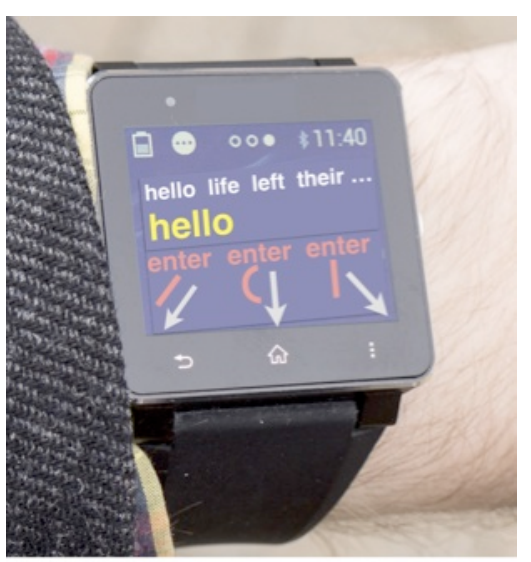

C

Figure 2: Three approaches for texting: a- one key per input primitive, b- directly drawing the input primitive, c- one flick per input primitive. (Red text and arrows are only for explaining the figure. They are not displayed on the screen of the watch).

The easiest adaptation is to use a 3-key keypad, each key corresponds to one input primitive, the enter key can be replace by a gesture. These keys can be placed on the side of the screen 
or in each corner (figure 2-a). Another way is to use the touch screen capability by directly drawing the shape of the input primitives (diagonal stroke, curve or straight line) on the screen (figure 2-b). Finally, it is also possible to use flick or swipe gestures on the screen to enter the input primitives and to control all the process steps of text entry. For example, a flick down-left for diagonal stroke, a flick down for curve stroke, a flick down-right for straight stroke (figure 3-c).

\section{The problem of word prediction}

As the input is ambiguous, the expected word is proposed by a linguistic predictor. The simplest way is to use the default predictor of the smartphone linked to the watch (QuickType for Aplle IOS, Next Word Prediction for Android, Sense Input for HTC...).

Assuming that only very simple posts with abbreviations (OK, IDTS, B4, 2C...) will be entered on the screen of a connected watch, it must be preferable to use a specific predictor [Agarwal, Arora, 2007].

In the final paper, UniWatch will be presented and the choice of the selected approach will be explained.

\section{References of this extended abstract}

- MacKenzie S., Tanaka-Ishii K. Text Entry Systems: Mobility, Accessibility, Universality. Editor : Morgan Kaufmann Publishers., 2007.

- Poirier F., Glyph: A New Stroke-Alphabet for Stylus-Based or Key-Based Text Entry, Proc. HCI Int 2005, Springer, 2005.

- Poirier F., Belatar M. UniGlyph: only one keystroke per character on a 4-button minimal keypad for key-based text entry. Proc. HCI Int 2007, Springer, 2007.

- Poirier F. Text Entry Methods For Handheld Devices Or For AAC Writing System. In Proceedings of the SIGCHI Conference on Human Factors in Computing Systems (CHI 2012). ACM Press, 2012.

- Agarwal S., Arora S. Context Based Word Prediction for Texting Language. In Proceedings of the 8th RIAO International Conference on Large-Scale Semantic Access to Content, 2007. 